\title{
The Relationship Between Resting Heart Rate and Age in Adult Nigerians
}

\author{
Peter Ekpunobi Chime ${ }^{1, \text { * }}$, Wilfred Okwudili Okenwa ${ }^{2}$, Bibiana Oti ${ }^{1}$ \\ ${ }^{1}$ Department of Medicine, Enugu State University of Science and Technology Teaching Hospital, Parklane, Enugu, Nigeria \\ ${ }^{2}$ Department of Surgery, Enugu State University of Science and Technology Teaching Hospital, Parklane, Enugu, Nigeria
}

Email address:

pe4chyme@yahoo.com (P. E. Chime), greatson2002@yahoo.com (W. O. Okenwa), bibiana84@hotmail.com (B. Oti)

${ }^{*}$ Corresponding author

\section{To cite this article:}

Peter Ekpunobi Chime, Wilfred Okwudili Okenwa, Bibiana Oti. The Relationship Between Resting Heart Rate and Age in Adult Nigerians. American Journal of Internal Medicine. Vol. 8, No. 4, 2020, pp. 172-176. doi: 10.11648/j.ajim.20200804.15

Received: June 24, 2020; Accepted: July 10, 2020; Published: July 17, 2020

\begin{abstract}
Background: Resting heart rate is related to cardiovascular mortality as well as to all-cause mortality. It is therefore important to know whether resting heart rate changes with age in adults. The aim of this study was to determine the relationship between heart rate and age in adult Nigerians. Methods: It was a retrospective study on adult Nigerians attending a University Teaching Hospital in Nigeria. All the needed data were retrieved from the medical records. Heart rate was calculated from the electrocardiogram and correlated with age. Results: There were 99 cases aged between 20 and 54 years and comprised of 60 males and 39 females. The mean heart rate was $73.40 \pm 13.16$ beats/minute. Across the various decades, the mean heart rate in beats per minute was $73.46 \pm 10.70$ in the third decade, $75.52 \pm 12.16$ in the fourth decade, $72.38 \pm 13.91$ in the fifth decade, and $71.60 \pm 18.77$ in the sixth decade of life $(\mathrm{p}=0.770)$. Heart rate correlated negatively and weakly with age $(\mathrm{r}=-$ $0.034, \mathrm{p}=0.736$ ). There were more cases of sinus bradycardia than sinus tachycardia, but the proportion of cases with heart rate outside 60 beats per minute to 100 beats per minute was small. Conclusion: This study showed that resting heart rate did not change with age in young adult and middle-aged Nigerians who had no clinical evidence of heart disease. A greater proportion of them were in normal sinus rhythm.
\end{abstract}

Keywords: Heart Rate, Age, Sinus Bradycardia, Sinus Tachycardia

\section{Introduction}

Resting heart rate is related to life expectancy [1]. Resting heart rate is also related to cardiovascular mortality as well as to all-cause mortality [2]. It is therefore important to know whether resting heart rate changes with age in adults. Presently, there are conflicting reports regarding the effect of age on resting heart rate in adults.

The relationship between resting heart rate and age has been well studied in children but not in adults. Heart rate peaks in the first month of life after which it decreases progressively [3]. Among the boys they studied, Rijnbeek et al [4] found the median heart rate to be 152 beats per min in the first to third month of life, decreasing to 98 beats per min in the third to fifth year of life, and decreasing further to 73 beats per min in the 12th to 16th year of life. Among the girls studied along with the boys, the respective median heart rates were slightly higher than those of the boys but followed a similar pattern [4].

In the case of adults, reports from studies on the relationship between resting heart rate and age have been inconsistent. Kostis et al [5] studied adults aged between 16 and 68 years in the USA, and reported that heart rate did not change significantly with age. However, in Japan, Shigetoh et al [6] studied adults aged between 21 and 71 years and reported a significant reduction in heart rate after a period of 20 years. In Nigeria, Ayoka et al [7] studied subjects aged between 20 and 30 years and found their heart rates to be between 61 and 93 beats per minute. However, the study did not report on the effect of age on heart rate. The lack of consensus on the effect of age on heart rate in adults has created a gap in knowledge. The purpose of this study was to 
fill this gap in knowledge. The objective of this study was to determine the relationship between resting heart rate and age among adult Nigerians.

\section{Methods}

The study was carried out at the Enugu State University of Science and Technology Teaching Hospital (ESUTH), Parklane, Enugu, Nigeria, a tertiary health center. The study cases were cases in which the heart rates were determined by electrocardiogram (ECG). The inclusion criteria were (a) age 18 years and above and (b) normal weight subjects (body mass index between 18.5 to 24.9). Cases with the following conditions which may affect the heart or cardiac electrophysiology were excluded from the study: (a) any case with a history of hypertension, heart disease, heart failure, diabetes mellitus, chronic obstructive pulmonary disease or kidney disease, (b) those on beta blocker or beta agonist and (d) pregnant females.

The study cases were recruited from among the cases which attended the medical outpatient clinics of the hospital between January 2015 and June 2015. First, the cases which did not have the medical conditions listed under exclusion criteria were listed from the medical outpatient clinic register. Because morbidities are common among patients presenting at the medical outpatient clinics, the number of cases listed from the registers were relatively small. Secondly, the medical records of the listed cases were scrutinized to see if they met the inclusion criteria and also to see if they do or do not have the conditions listed under the exclusion criteria. The first 100 cases which met the eligibility criteria were finally recruited for the study. One of the recruited cases was eventually dropped because of the discrepancy between the age recorded in the medical record and the age recorded on the ECG.

Statistical analyses of data were done with statistical product and service solutions (SPSS) software version 22
(IBM Statistics, IBM Corp). Group means were compared using analysis of variance (ANOVA). Also, using bivariate correlation and Person correlation coefficient, the relationship between heart rate and age was determined. The frequencies of bradycardia and tachycardia in the different groups were compared using chi-square test and the results presented as number (percent (\%)). Statistical values with probabilities less than 0.05 were considered significant. Results were presented in tabular and graphic forms.

\section{Results}

There were 99 cases comprising of 60 males and 39 females. They were aged between 20 and 54 years with a mean age of $40.01 \pm 8.02$ years. Their heart rate ranged from 51 to 106 beats/minute, with a mean of $73.40 \pm 13.16$ beats/minute.

In beats $/ \mathrm{min}$, the mean heart rate was $73.46 \pm 10.70$ in the third decade, $75.52 \pm 12.16$ in the fourth decade, $72.38 \pm 13.91$ in the fifth decade, and $71.60 \pm 18.77$ in the sixth decade of life. However, the differences were not statistically significant $(\mathrm{p}=0.770)$. See Table 1 .

Overall, there was a negative correlation between heart rate and age, but the correlation was very weak $(\mathrm{r}=-0.034$, $\mathrm{p}=0.736$ ). See Figure 1 and Table 2 .

The correlation between heart rate and age was also very weak in each of the four decades: i.e., third decade, fourth decade, fifth decade, and sixth decade of life $(p>0.05$ in each case). See Table 2.

Sinus bradycardia was observed in the third decade $(7.7 \%)$, fourth decade $(10.3 \%)$ and fifth decade $(11.5 \%)$ but with no statistically significant differences. The overall prevalence of bradycardia was $10.1 \%$.

Sinus tachycardia was observed only in the fourth decade (3.4\%), fifth decade (3.8\%) and sixth decade (20.0\%), with no statistically significant difference. The overall prevalence of tachycardia was $4.0 \%$.

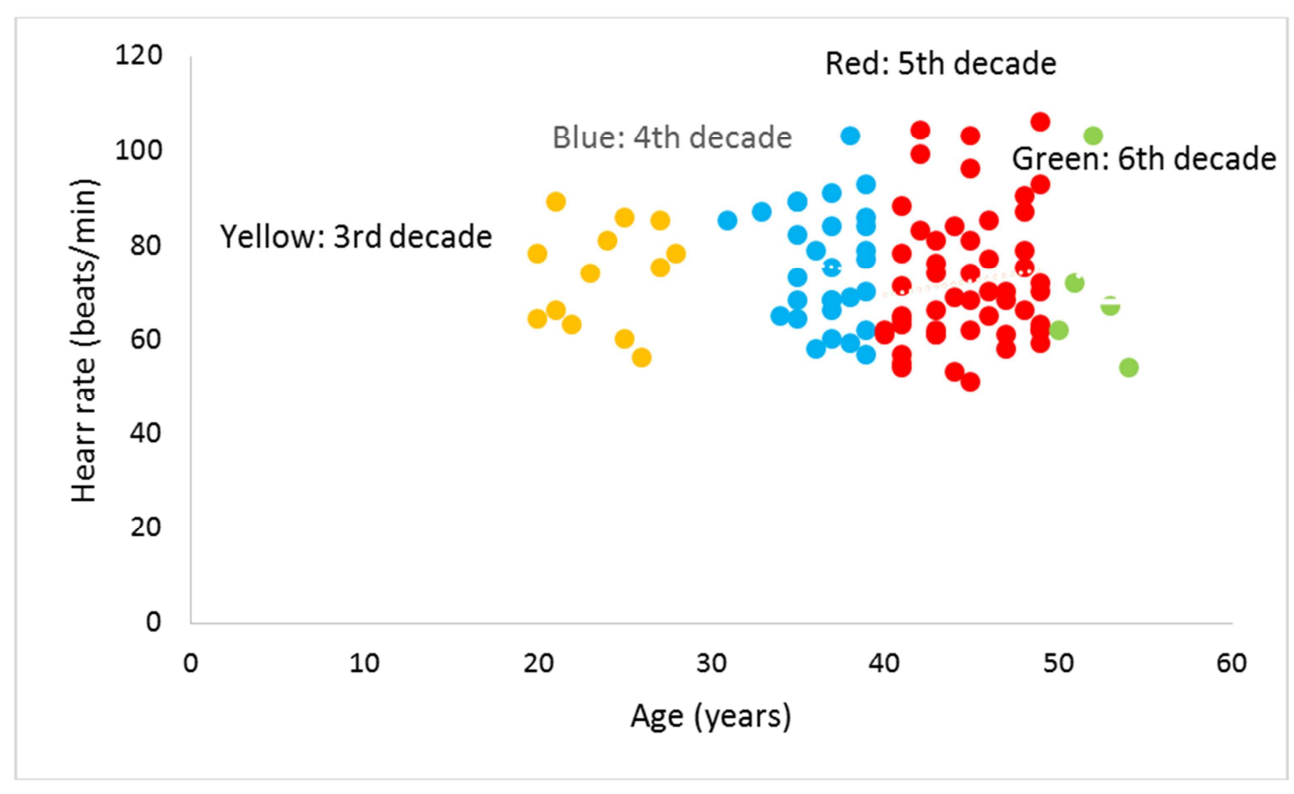

Figure 1. Heart rates at various decades of life. 


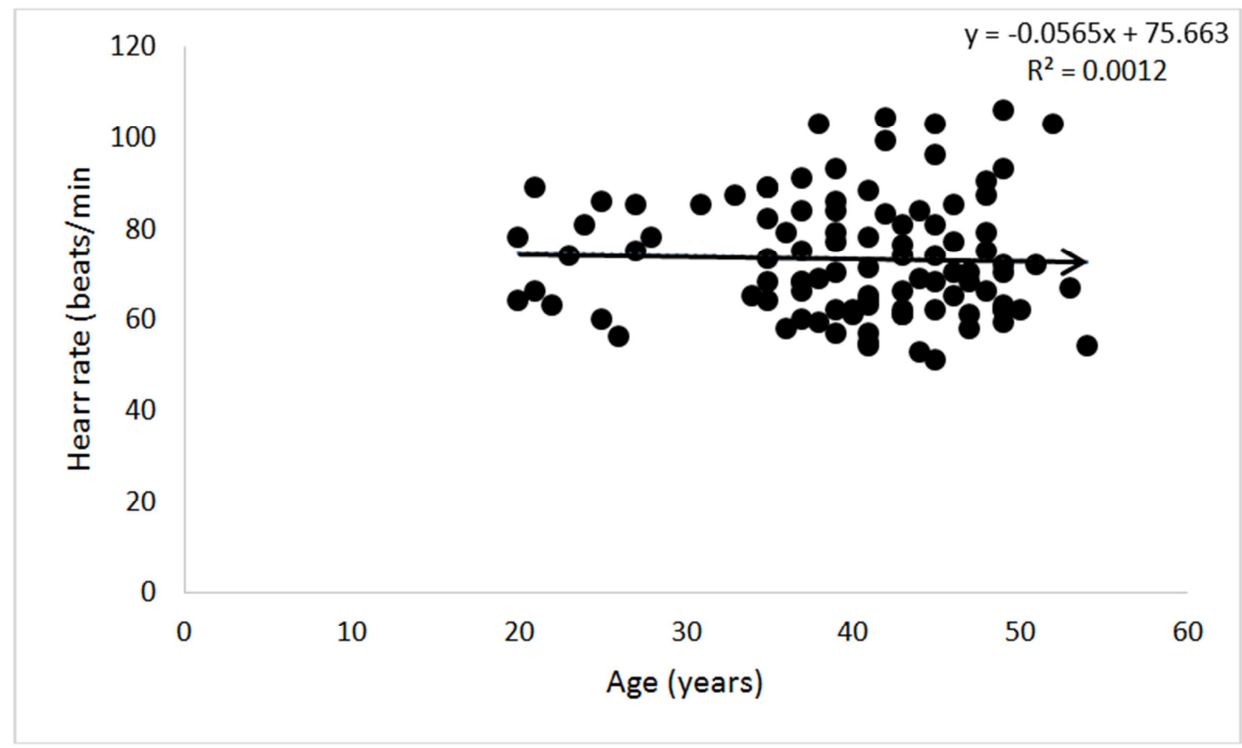

Figure 2. Heart rate is negatively but very weakly correlated with age.

Table 1. Heart rates of the studied cases.

\begin{tabular}{|c|c|c|c|c|c|c|}
\hline & $\begin{array}{l}\text { Third decade } 20 \\
-29 \text { years } \\
(n=13)\end{array}$ & $\begin{array}{l}\text { Fourth decade } \\
30-39 \text { years } \\
(n=29)\end{array}$ & $\begin{array}{l}\text { Fifth decade } 40- \\
49 \text { years }(n=52)\end{array}$ & $\begin{array}{l}\text { Sixth decade } \\
50-59 \text { years } \\
(n=5)\end{array}$ & $\begin{array}{l}\text { Total } 20-59 \text { years } \\
(n=99)\end{array}$ & P-value \\
\hline Age & $23.77 \pm 2.80$ & $36.72 \pm 2.07$ & $44.75 \pm 2.94$ & $52.00 \pm 1.58$ & $40.01 \pm 8.02(20-54)$ & 0.000 \\
\hline Mean heart rate $(\mathrm{b} / \mathrm{m})$ & $73.46 \pm 10.70$ & $75.52 \pm 12.16$ & $72.38 \pm 13.91$ & $71.60 \pm 18.77$ & $73.40 \pm 13.16(51-106)$ & 0.770 \\
\hline Frequency of sinus bradycardia & $1(7.7 \%)$ & $3(10.3 \%)$ & $6(11.5 \%)$ & $0(0.0 \%)$ & $10(10.1 \%)$ & 0.858 \\
\hline Frequency of sinus tachycardia & $0(0.0 \%)$ & $1(3.4 \%)$ & $3(3.8 \%)$ & $1(20.0 \%)$ & $4(4.0 \%)$ & 0.277 \\
\hline
\end{tabular}

Table 2. Correlation of heart rate with age.

\begin{tabular}{llllll}
\hline & $\begin{array}{l}\text { Third decade 20 - } \\
\mathbf{2 9} \text { years (n=13) }\end{array}$ & $\begin{array}{l}\text { Fourth decade 30 } \\
\mathbf{- 3 9} \text { years (n=29) }\end{array}$ & $\begin{array}{l}\text { Fifth decade 40 - } \\
\mathbf{4 9} \text { years }(\mathbf{n}=\mathbf{5 2})\end{array}$ & $\begin{array}{l}\text { Sixth decade 50 }- \\
\mathbf{5 9} \text { years (n=5) }\end{array}$ & $\begin{array}{l}\text { All together } \\
(\mathbf{n}=\mathbf{9 9})\end{array}$ \\
\hline Person correlation coefficient $(\mathrm{R})$ & 0.104 & -0.147 & 0.129 & -0.177 & -0.034 \\
$\mathrm{p}$ value & 0.736 & 0.439 & 0.361 & 0.776 & 0.736 \\
\hline
\end{tabular}

\section{Discussion}

The relationship between resting heart rate and age

This study examined the relationship between resting heart rate and age in adult Nigerians. The clinical importance of resting heart rate is its relationship with life expectancy [1] as well as with cardiovascular and all-cause mortality [2]. Yet, the relationship between resting heart rate and age in adults has not been established by previous studies, as reports have been conflicting, thus making further studies necessary.

Ninety-nine cases were analyzed. Their mean age was $40.01 \pm 8.02$ years and their mean heart rate was $73.40 \pm 13.16$ beats per minute. On inter-decade analyses, the mean heart rate decreased progressively but non-significantly from the fourth decade through the fifth decade to the sixth decade of life.

The result of this study is in agreement with those of Kostis et al [5] but is contrary to those of Shigetoh et al [6]. Kostis et al [5] conducted ambulatory electrocardiography on 101 adults with apparently normal hearts who were aged between 16 and 68 years with a mean age of 48.8 years, and reported that their heart rate did not change with age. Their ambulatory night time mean heart rate was 70.0 beats per minute. Their ambulatory day time mean heart rate was expectedly higher (78.9 beats per minute) because of physical activities. But in a study in Japan on a rural farming community aged between 21 and 71 years (mean age 43.2 years), Shigetoh et al [6] found them to have a mean heart rate of 67 beats per minute. Twenty years later, when their mean age had increased to 62.7 years (range $41-90$ years), their mean heart rate was reported to have decreased significantly to 63 beats per minute.

Knox [8] had much earlier on studied 75 male medical students aged between 18 and 22 years and found their mean heart rate to be 85.7 beats per minute. However, Knox considered that to be high, and commented that earlier researchers had documented the mean heart rate in a similar age group to be $71-72$ beats per minute and $70-72$ beats per minute, respectively. Although, the studies quoted by Knox were published in 1850 and 1939 respectively, they are in agreement with a more recent publication. In a recent systematic review and meta-analysis published in 2018, involving 6763 subjects and 6189 controls, Reimers et al [9] reported their mean heart rate to be 72.4 beats per minute and 
72.3 beats per minute respectively. These figures are close to that reported in the current study as well as that reported by Kostis et al. It is important to note, however, that gender differences in heart rate [10] as well as racial differences in electrocardiographic parameters [11] have been highlighted by previous researchers. Also, racial differences in electrocardiographic abnormalities has been reported [12].

Correlation between heart rate and age

Studies in children showed that heart rate is positively correlated with age in the first month of life [3], and negatively correlated with age from the first month of life to the 12 th to 16 th year of life [4].

In the case of adults, the current study reported nonsignificant negative correlation between heart rate and age across the fourth decade, fifth decade and sixth decade of life. The study by Shigetoh et al [6] which reported a significant decrease in heart rate after a period of 20 years also implied that heart rate has a negative correlation with age in the age group they studied. The study by Palhares et al [13] was very extensive, covering from one year of age to over 90 years of age. The study showed heart rate to be negatively correlated with age from the first year of age to the 19 years of age, in both males and females. Palhares et al reported that heart rate stabilized "around 65-66 bpm from 20 to 79 years" and increased to "70 bpm after 90 years" of age [13]. However, it was not shown in the report whether the increase in heart rate after 90 years of age was statistically significant or not.

The prevalence of sinus bradycardia and sinus tachycardia

For the purposes of this study, sinus tachycardia was defined as sinus heart rhythm persistently greater than 100 beats per minute and sinus bradycardia was defined as sinus heart rhythm persistently less than 60 beats per minute [14]. There were more cases of sinus bradycardia (10.1\%) in this study than cases of sinus tachycardia (4.0\%). The preponderance of sinus bradycardia was similar to what His and Lamb [14] found in their own study. The difference between the two studies was that the prevalence of sinus bradycardia His and Lamb recorded in their own study was much higher than what was recorded in the current study. Prevalence of sinus bradycardia: $23.76 \%$ versus $10.1 \%$. Prevalence of sinus tachycardia: $3.11 \%$ versus $4.0 \%$. This difference might be due the characteristics of the subjects studied. Those studied by His and Lamb were active Air Force personnel, while those in the current study were mainly civilians. In another study in China in adults [15], the prevalence of sinus bradycardia and sinus tachycardia in nonHIV positive subjects followed a similar pattern recorded in this study in which the prevalence of sinus bradycardia was higher than the prevalence of sinus tachycardia (prevalence of bradycardia, 9.4\%; prevalence of tachycardia, 1.3\%).

\section{Conclusion and Recommendation}

Among young adult and middle-aged Nigerians who had no clinical evidence of heart disease, there was no significant decrease in heart rate with increasing age. The correlation between heart rate and age in this age group was negative but very weak. The proportion of people with sinus bradycardia and sinus tachycardia was small as majority of them were in normal sinus rhythm.

Future studies on the relationship between resting heart rate and age in adults should attempt a prospective approach as well as employ a large sample size that will cover the age groups beyond the sixth decade of life. This will help to understand the effect of age on the resting heart rate of the elderly population.

\section{The Limitation of the Study}

The data analyzed in this study were not longitudinal data. However, similar studies in children which gave insight into the relationship between heart rate and age in children were also based on non-longitudinal data.

\section{The Strength of the Study}

The data analyzed in this study were from subjects in whom there was no clinical evidence of any disease that might affect the heart.

\section{Conflicts of Interest}

The authors declare that they have no competing interests.

\section{References}

[1] Hartaigh B. O., Gill T. M., Shah I., Hughes A. D., Deanfield J. E., Kuh D., Hardy R. Association between resting heart rate across the life course and all-cause mortality: Longitudinal findings from the Medical Research Council (MRC) National Survey of Health and Development (NSHD) J. Epidemiol. Community Health. 2014; 68: 883-889. doi: 10.1136/jech2014-203940. [PMC free article] [PubMed] [CrossRef] [Google Scholar].

[2] Nauman J, Janszky I, Vatten LJ, et al. Temporal changes in resting heart rate and deaths from ischemic heart disease. JAMA. 2011; 306: 2579-2587. [PubMed] [Google Scholar].

[3] Fleming S, Thompson M, Stevens R, Heneghan C, Pluddemann A, Maconochie I, Tarassenko L, Mant D. Normal ranges of heart rate and respiratory rate in children from birth to 18 years: a systematic review of observational studies. Lancet. $\quad 2011 \mathrm{Mar} \quad 19 ; 377$ (9770): 1011-1018. https://www.ncbi.nlm.nih.gov/pmc/articles/PMC3789232/.

[4] Rijnbeek PR, Witsenburg M, Schrama E, et al. New normal limits for the paediatric electrocardiogram. Eur Heart $J$ 2001; 22: $702-11$.

[5] Kostis JB, Moreyra AE, Amendo MT, Di Pietro J, Cosgrove N, Kuo PT. The Effect of Age on Heart Rate in Subjects Free of Heart Disease. Studies By Ambulatory Electrocardiography and Maximal Exercise Stress Test. Circulation 65, No. 1, 1982. 141-145.

[6] Shigetoh Y, Adachi H, Yamagishi S et al. Higher heart rate may predispose to obesity and diabetes mellitus: 20-year prospective study in a general population. Am. J. Hypertens. 22, 151-155 (2009). 
[7] Ayoka AO, Ogunlade IO, Akintomide O, Akomolafe RO, Ajayi OE. Normal Limits of Electrocardiogram and Cut-Off Values for Left Ventricular Hypertrophy in Young Adult Nigerians. Niger. J. Physiol. Sci. 29 (June 2014) 063-066.

[8] Knox JA. The Heart Rate During A Simple Exercise. Br Heart J. 1940; 2 (4): 289-297. doi: 10.1136/hrt.2.4.289.

[9] Reimers AK, Knapp G, Reimers CD. Effects of Exercise on the Resting Heart Rate: A Systematic Review and MetaAnalysis of Interventional Studies. J Clin Med. 2018; 7 (12): 503. Published 2018 Dec 1. doi: 10.3390/jcm7120503.

[10] Pinto MM Filho, Brant LCC, Padilha-da-Silva JL, et al. Electrocardiographic Findings in Brazilian Adults without Heart Disease: ELSA-Brasil. Arq Bras Cardiol. 2017; 109 (5): 416-424. doi: 10.5935/abc.20170146.

[11] Alame AJ, Garg S, Kozlitina J, et al. Association of African Ancestry With Electrocardiographic Voltage and Concentric Left Ventricular Hypertrophy: The Dallas Heart Study. JAMA Cardiol. 2018; 3 (12): 1167-1173. doi: 10.1001/jamacardio.2018.3804
[12] Pinto-Filho MM, Brant LC, Foppa M, Garcia-Silva KB, Mendes de Oliveira RA, de Jesus Mendes da Fonseca M, et al. Major electrocardiographic abnormalities according to the Minnesota Coding System among Brazilian adults (from the ELSA-Brasil Cohort Study) Am J Cardiol. 2017; 119 (12): 2081-2087. doi: 10.1016/j.amjcard.2017.03.043. [PubMed] [CrossRef] [Google Scholar].

[13] Palhares, D. M., Marcolino, M. S., Santos, T. M. et al. Normal limits of the electrocardiogram derived from a large database of Brazilian primary care patients. BMC Cardiovasc Disord 17, 152 (2017). https://doi.org/10.1186/s12872-017-0572-8.

[14] Hiss RG, Lamb LE. Electrocardiographic findings in 122,043 individuals. Circulation. 1962 Jun; 25: 947-961. [PubMed] [Google Scholar].

[15] Ding Y, Zhu B, Lin H, Chen X, Shen W. HIV infection and electrocardiogram abnormalities: baseline assessment from the CHART cohort. Clinical Microbiology and Infection. Available online 17 March 2020. In Press, Corrected Proof https://doi.org/10.1016/j.cmi.2020.03.005. Accessed on 9/7/2020. 